\title{
Optical PIV and LDV Comparisons of Internal Flow Investigations in SHF Impeller
}

\author{
G. Wuibaut, ${ }^{1}$ G. Bois, ${ }^{1}$ M. El Hajem, ${ }^{2}$ A. Akhras, ${ }^{2}$ and J. Y. Champagne ${ }^{2}$ \\ ${ }^{1}$ Laboratoire de Mécanique de Lille (UMR CNRS 8107), ENSAM, 8 boulevard Louis XIV, 59046 Lille Cedex, France \\ ${ }^{2}$ LMFA, UMR-CNRS 5509, Composante INSA-Lyon, avenue A. Einstein, 69621 Villeurbanne, France
}

Received 17 May 2005; Accepted 8 November 2005

The paper presents a comparison between two sets of experimental results in a centrifugal flow pump. The tested impeller is the so-called SHF impeller for which many experimental data have been continuously produced to built databases for CFD code validations with various levels of approximation. Measurements have been performed using optical techniques: 2D particle image velocimetry (PIV) technique on an air test model and 2D laser doppler velocimetry (LDV) technique on a water model, both for different flow rates. For the present study, results obtained by these optical techniques are compared together in terms of phase averaged velocity and velocity fluctuations inside the impeller flow passage for design flow rate.

Copyright ( $) 2006$ G. Wuibaut et al. This is an open access article distributed under the Creative Commons Attribution License, which permits unrestricted use, distribution, and reproduction in any medium, provided the original work is properly cited.

\section{INTRODUCTION}

LDV technique has already been recognised to give accurate measurements of temporal representation of velocity distribution in a spatial location of a turbomachine allowing interaction analysis between the impeller and its surroundings. A number of authors have treated this kind of problem like Miner et al. [1] for the case of volute. Liu et al. [2], Inoue and Cumpsty [3], and Arndt et al. [4] have been concerned with the influence of vaned diffuser. However, more detailed experimental data are needed to allow design techniques to take into account unsteady effects. Particle image velocimetry (PIV) appears to be a very useful nonintrusive technique for a better understanding of phenomena associated with rotor-stator interactions at design and offdesign conditions. Up to now, this technique is not so widely used as LDV to perform investigations of internal flow pattern of turbomachinery especially in air test rig. A few results are given for the case of vaneless diffuser by Hayashi et al. [5], more detailed measurements in water have been performed since 1988 by Paone et al. [6], Eisele et al. [7], Ciocan et al. [8], Sinha and Katz [9], and Pedersen and Jacobsen [10].

Among the several results obtained for SHF impeller, the paper only focuses on the internal flow characteristics at design flow conditions. The full data analysis and experimental conditions were described by Akhras [11] for LDV measurements and Wuibaut [12] for the PIV ones.

\section{EXPERIMENTAL CONFIGURATIONS}

Air and water test rigs have already been described in several papers and have different configurations. For the air tests case, the impeller casing is axisymmetric, as the impeller is only fitted with a vaneless diffuser and no volute as described by Wuibaut $[12,13]$. For the water test case, the impeller is followed by a vaned diffuser and a spiral casing volute of industrial type (Akhras et al. [14], El Hajem et al. [15]). The test impeller, shown in Figure 1, is a low specific speed $\left(\omega_{s}=0.577\right)$ shrouded impeller. It has seven backswept blades with an exit angle of 22.5 degrees relative to the tangential direction. The outlet part of that impeller is characterised by a $2 \mathrm{D}$ design. The main dimensions and operating conditions of the air and the water test models are listed in Table 1. Reynolds number based on outlet radius, speed of rotation, and dimensions is greater than $7 \times 10^{5}$ and is about five times greater in water than in air.

\section{EXPERIMENTAL RESULTS}

In order to allow comparison between LDV and PIV measurements in such different diffuser configuration, it is necessary to refer to the paper presented by Akhras et al. [14], where detailed LDV results in water show that impellerdiffuser interaction is limited to the impeller exit and has a limited influence on the internal impeller flow at design 


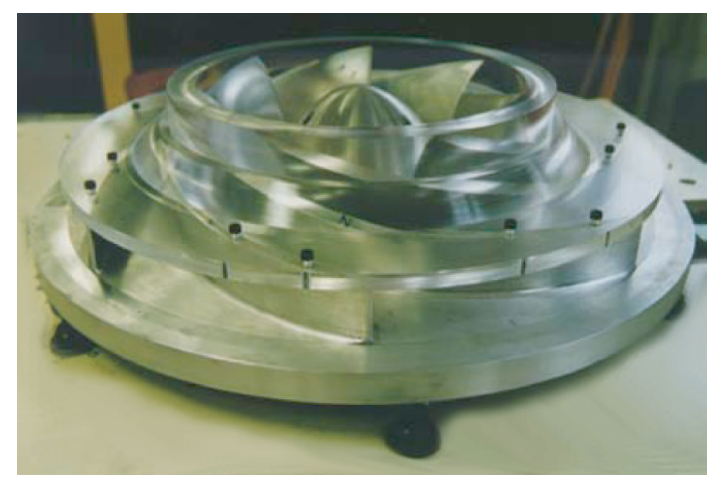

FIgURE 1: The SHF impeller.

TABle 1: Main characteristics of the test impellers.

\begin{tabular}{l|cc}
\hline Characteristics & Air & Water \\
\hline $\mathrm{R}_{1}$ & $142.2 \mathrm{~mm}$ & $98.25 \mathrm{~mm}$ \\
$\mathrm{R}_{2}$ & $256.6 \mathrm{~mm}$ & $177.25 \mathrm{~mm}$ \\
$\mathrm{~B}_{2}$ & $38.5 \mathrm{~mm}$ & $26.7 \mathrm{~mm}$ \\
$\mathrm{~N}$ & $1710 \mathrm{rpm}$ & $1188 \mathrm{rpm}$ \\
$\mathrm{Q}$ & $0.336 \mathrm{~m}^{3} / \mathrm{s}$ & $0.0774 \mathrm{~m}^{3} / \mathrm{s}$ \\
$\varphi$ & 0.118 & 0.118 \\
$\psi$ & 0.481 & 0.481 \\
$\omega_{s}$ & 0.577 & 0.577 \\
$\mathrm{Re}$ & $0.786 \times 10^{6}$ & $3.9 \times 10^{6}$ \\
\hline
\end{tabular}

conditions. Only the mixing process of the flow at discharge is affected by the presence of the diffuser vanes. Furthermore, PIV measurements performed for different flow rates by Wuibaut et al. [16] have shown that vaneless diffuser flow does not affect the relative impeller flow in the vicinity of the design mass flow rate.

\subsection{Measurements sections}

For PIV measurements in air, five measuring planes in the hub-to-shroud direction have been selected. Two different views allow to cover the outlet of the impeller and the vaneless diffuser region, these planes can be seen in Section 3.2.2. According to experimental technique described in Wuibaut et al. [16], in every measuring plane, up to 230 instantaneous velocity maps are available for the chosen operating point in the absolute frame of reference.

Each velocity map has been obtained for a precise position of the impeller by means of an angle encoder used for the synchronisation of the YAG-pulsed laser. According to the various sources of uncertainties, the relative uncertainty of instantaneous flow absolute velocity, in each point of the measurement grid, has been estimated to a maximum of $2 \%$. For LDV measurements in water, because of the vaned diffuser configuration following the studied impeller, flow was investigated at seven radial planes located at ten different angular positions relative to diffuser vanes as shown in Figure 2 (positions I to X). Three radial positions inside the impeller

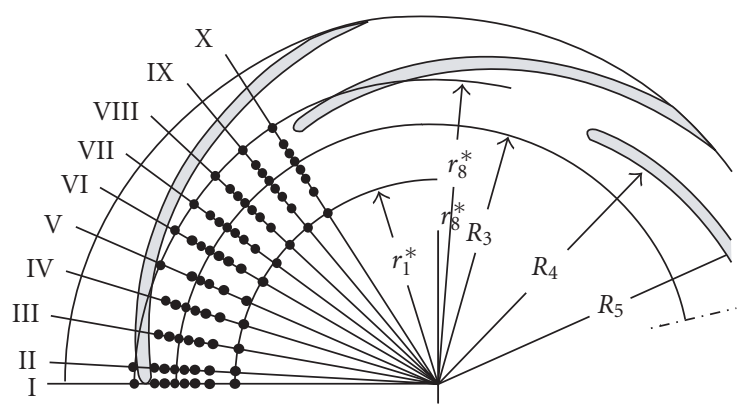

FIGURE 2: The ten angular and radial positions relative to diffuser vane for LDV measurements.

passage correspond to values $r^{*}=0.8182,0.9092,0.9784$. For each radius, sixteen points were explored.

\subsection{PIV and LDV results comparisons on mean relative velocities and fluctuations}

\subsubsection{Mean velocities}

In order to make these comparisons, local values of the PIV mean relative velocity and the PIV nondimensional velocity fluctuation rates have been extracted for several radii inside the impeller in order to plot them in the blade-to-blade plane with the LDV measuring sections. Five hub-to-shroud locations are presented for two radial positions $r^{*}=0.818$ and $r^{*}=0.978$. The nondimensional mean relative velocities are presented in Figures 3 and 4. Each figure represents the $\mathrm{W} / \mathrm{U}_{2}$ evolutions obtained by LDV technique (a) and PIV technique (b) for the different locations $b^{*}$. The velocity distribution from pressure to suction side is given as a function of $\theta /(2 \pi / 7)$, the blade pressure side corresponds to $\theta /(2 \pi / 7)=0$.

As already reported by Eckardt [17] and Ubaldi et al. [18] for the same kind of geometry, it appears that the impeller suction side corner is dominated by important relative velocity gradient and an accumulation of low-momentum fluid developing in the so-called "wake" region. As reported in [12], the lack of relative velocity in the shroud-suction side corner of the impeller passage is related to low radial velocity component associated with increasing tangential absolute velocity component. Consequently, the relative angle $\beta$ evolution near the shroud increases near the suction side. As these local values cannot be higher than the geometrical blade angle, one can suppose that this increase of $\beta$ with low radial component may be associated with $3 \mathrm{D}$ radial to axial flows in the shroud-suction side corner.

Note that for the PIV results, one has to keep in mind that results may also be affected by flare problems due to the blade side. As a consequence, LDV measurements give more detailed results than PIV ones very near the suction side. Generally speaking, comparing PIV and LDV measurements results, one can make the following comments.

(a) For $r^{*}=0.818$, the wake region is located mainly after the blade midheight $\left(b^{*}=0.5\right)$, both for LDV and PIV 

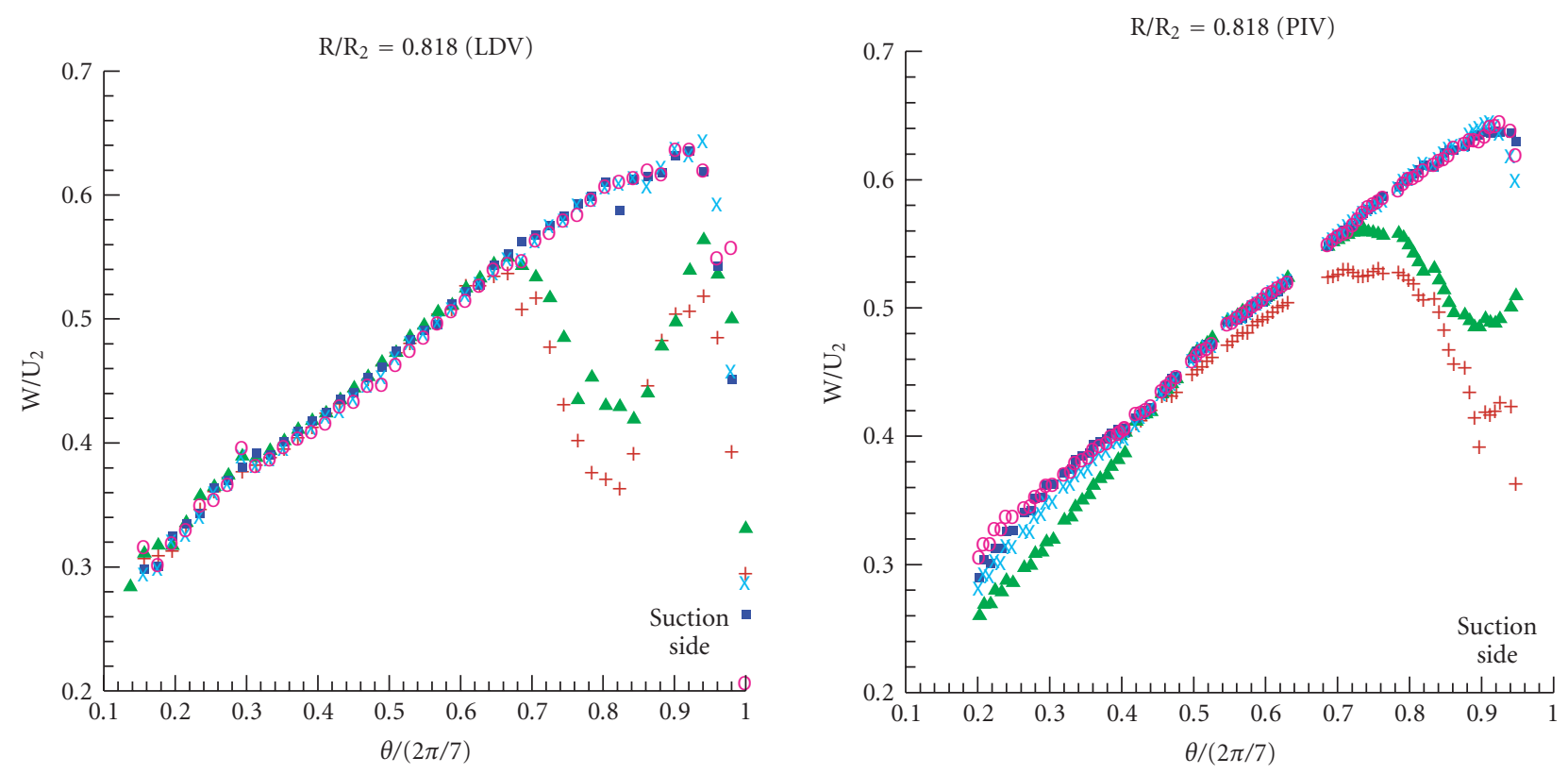

$+\mathrm{B} / \mathrm{B}_{3}=0.831$
- $\mathrm{B} / \mathrm{B}_{3}=0.719$
- $\mathrm{B} / \mathrm{B}_{3}=0.494$

$\times \mathrm{B} / \mathrm{B}_{3}=0.270$

$+\mathrm{B} / \mathrm{B}_{3}=0.871$

$\times \mathrm{B} / \mathrm{B}_{3}=0.256$

$\Delta \mathrm{B} / \mathrm{B}_{3}=0.743$

$\mathrm{O} B / \mathrm{B}_{3}=0.128$

- $\mathrm{B} / \mathrm{B}_{3}=0.5$

(a)

(b)

FIgURE 3: Evolutions of $\mathrm{W} / \mathrm{U}_{2}$ in the blade-to-blade direction at a constant radius $r^{*}=0.818$.

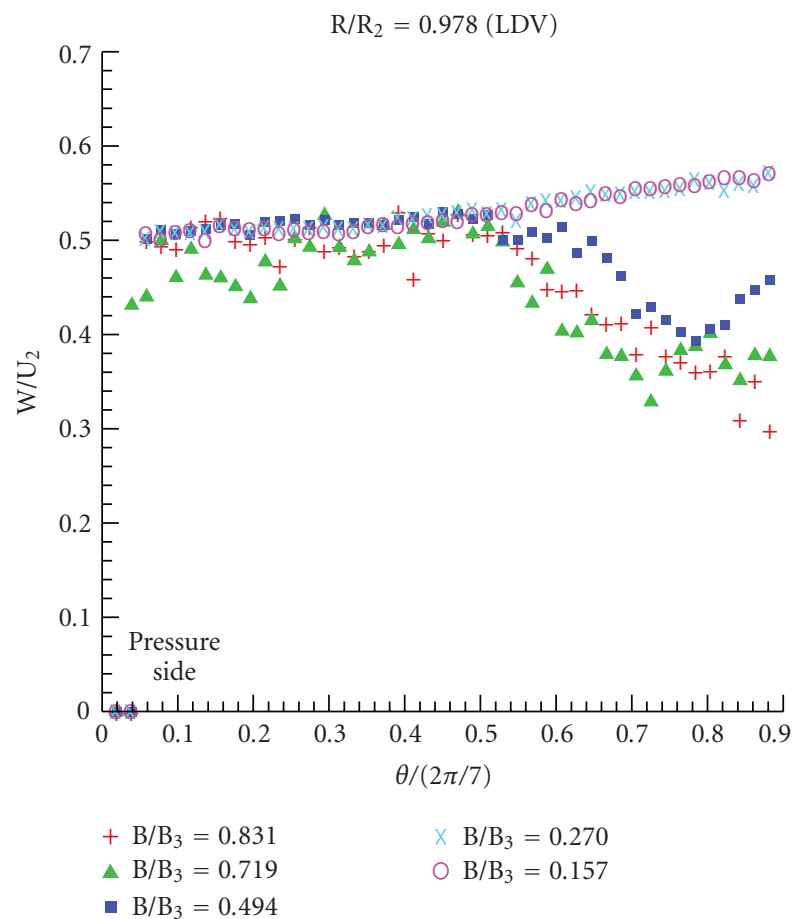

(a)

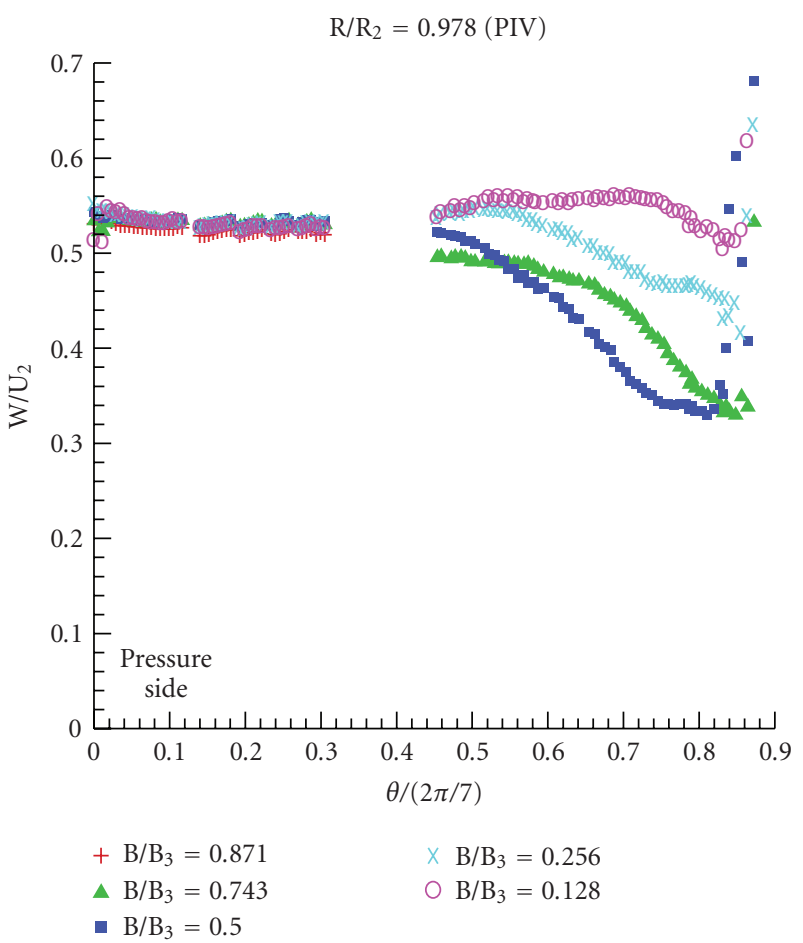

(b)

FIGURE 4: Evolutions of W/ $\mathrm{U}_{2}$ in the blade-to-blade direction at a constant radius $r^{*}=0.978$. 


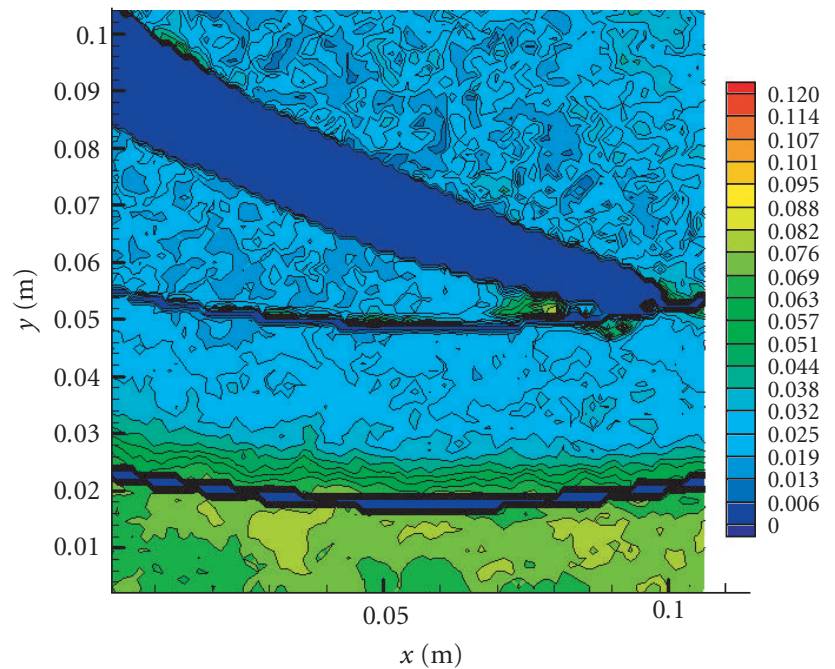

(a) $b^{*}=0.128$

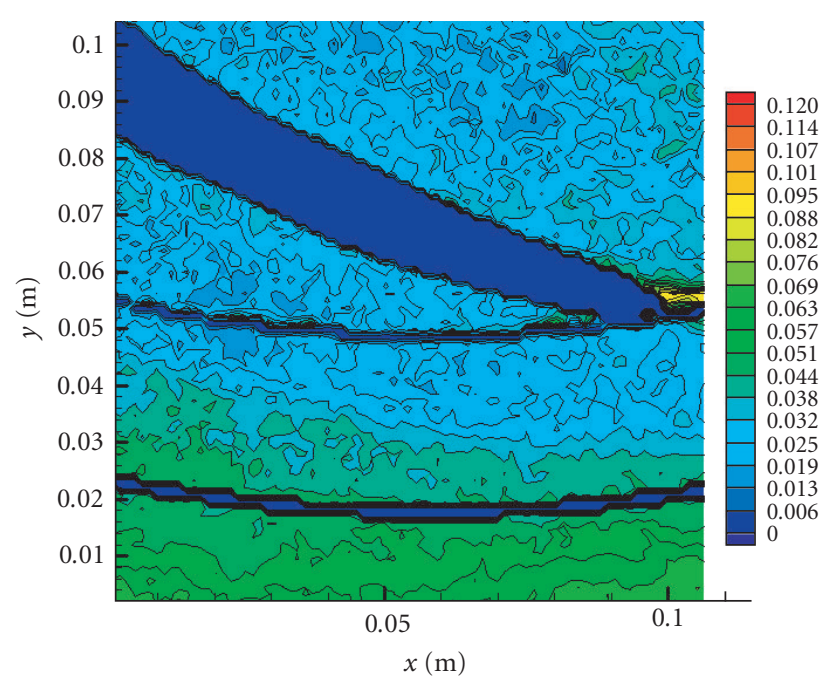

(c) $b^{*}=0.5$

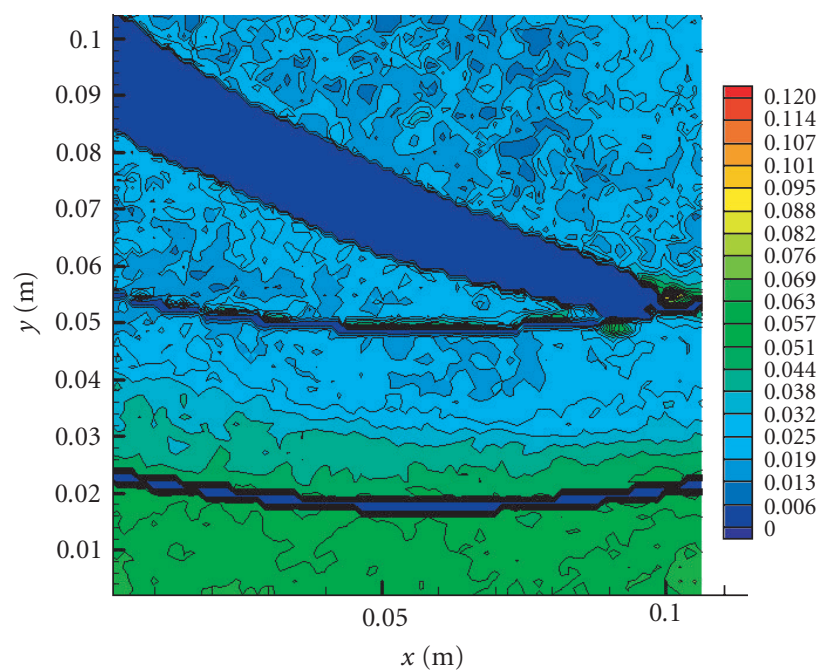

(b) $b^{*}=0.256$

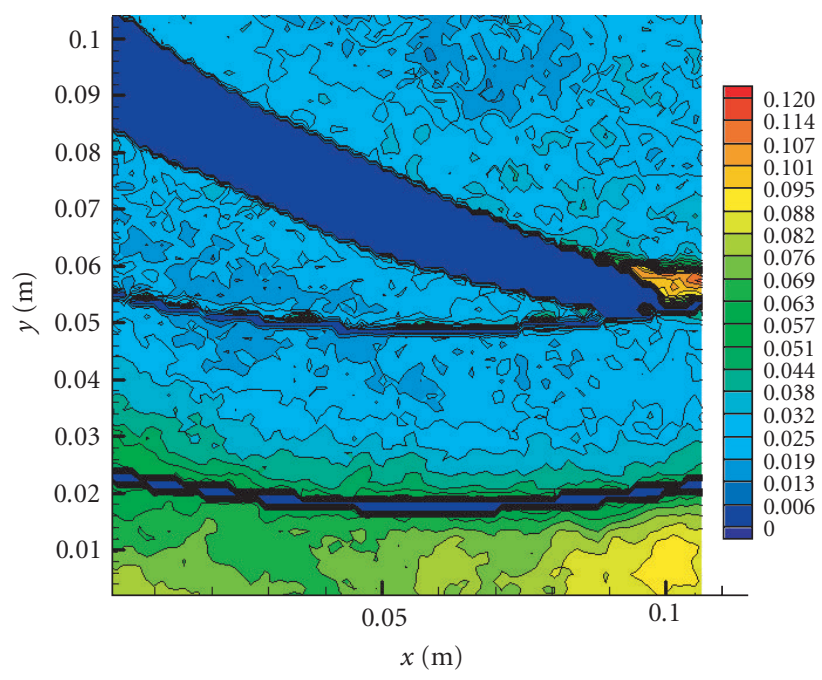

(d) $b^{*}=0.743$

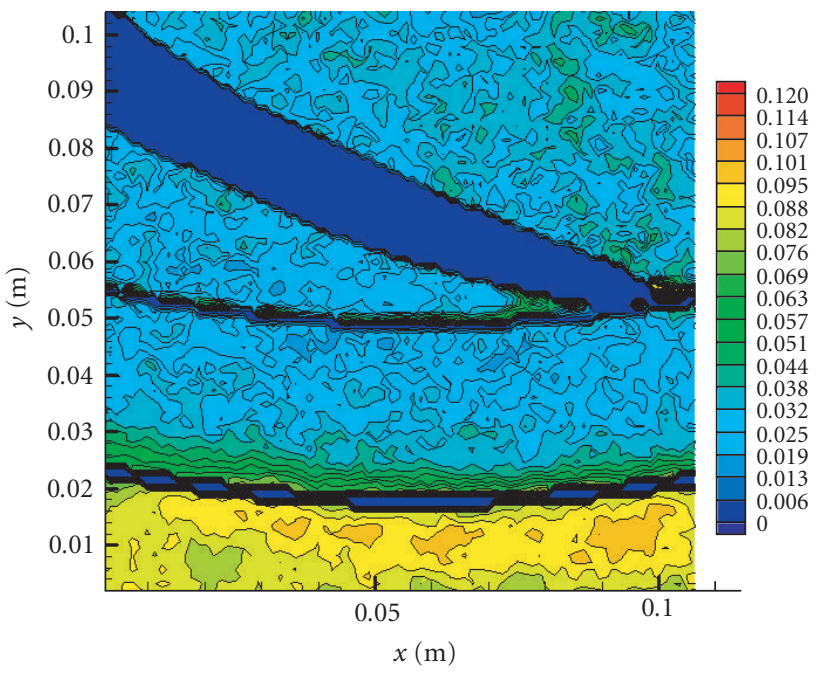

(e) $b^{*}=0.871$

FIGURE 5: Velocity fluctuation rates. 
results. From hub to blade midheight, the relative velocity gradient and local level are very similar.

(b) At impeller outlet section $\left(r^{*}=0.978\right)$, one can observe first the modification of the relative velocity gradient. This is commonly observed near the trailing edge region of centrifugal machines. A particular evolution can be seen in the wake. The LDV measurements indicate a minimum of velocity values for $b^{*}=0.7$ whereas PIV results show that the lowest velocity values are reached for $b^{*}=0.5$ corresponding to a more pronounced displacement of this particular region associated with the centre part of the wake compared with LDV results. It can be seen that LDV results show a more important wake growth than PIV ones whatever the radial location in the impeller blade passage is. These experimental results differences of the local flow pattern of the wake location and expansion can be explained taking into account several points.

(i) Measurement uncertainties: first one has to keep in mind that the relative uncertainty of absolute velocity components from which relative velocities are derived has been estimated to $2 \%$.

(ii) Plane location error: in addition, the axial position of measuring plane location is known with a possible error of $\pm 0.5 \mathrm{~mm}$ due to the thickness of the PIV laser sheet. This corresponds to a relative error of the measuring plane position about $2.5 \%$ along the impeller width. So that, because of the existing important relative velocity gradients that are observed, near midblade height, it is possible to have local differences between the two experimental techniques.

(iii) Inlet recirculation: air and water test rigs have different geometrical arrangements, so that inlet recirculation effects due to leakage flow are not controlled.

(iv) One has to keep in mind that these considerations and comparisons are only based on the mean relative velocity fields. More detailed investigations based on velocity components (in particular the radial velocity) and turbulence levels may show local interactions inside the impeller blade passage. This will be discussed in the next section.

\subsubsection{Velocity fluctuation rates}

Before starting the comparisons between PIV and LDV results, PIV views showing the outlet part of the impeller and part of the vaneless diffuser have been chosen. In these particular views, the nondimensional velocity fluctuation rate deduced from PIV measurements is shown in Figures 5(a) to $5(\mathrm{e})$, for five plane locations between hub $\left(b^{*}=0\right)$ and shroud $\left(b^{*}=1\right)$. Another view is added in Figure 6 for more details concerning another part of the impeller outlet just after the trailing edge and part of the vaneless diffuser. The velocity fluctuation rates remain at the same level of magnitude in the vicinity of the pressure side of the impeller (near 2.5\%) near the hub regions (Figures 5(a) and 5(b)). For $b^{*}=0.128$, it is possible to detect slightly higher rates corresponding to the hub boundary layer. Looking at the evolution from Figures 5(a) to 5(e), one can see that the low rate of the velocity

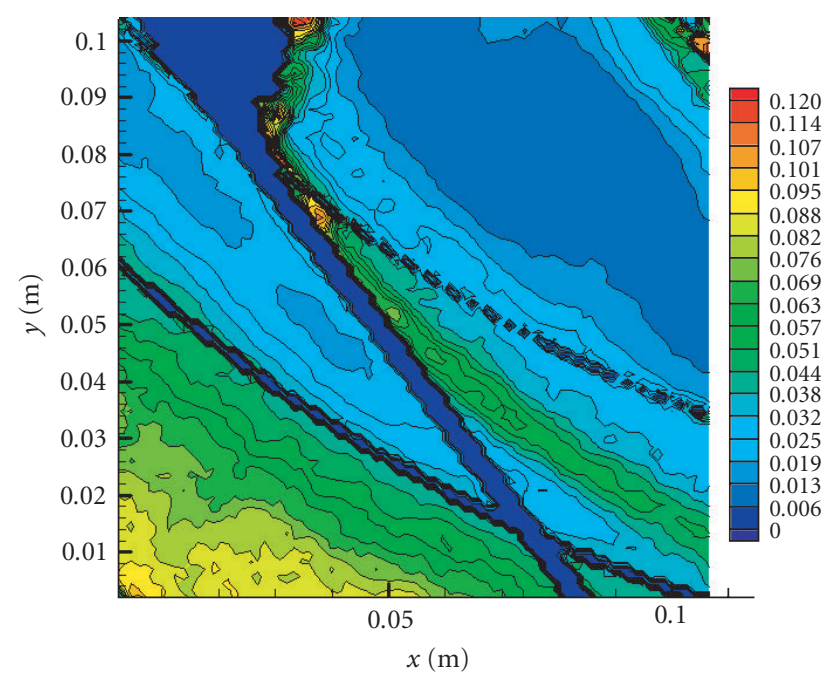

FIgURE 6: Velocity fluctuations in the passage wake.

fluctuations seems to be pushed away from the impeller pressure side towards the mid blade-to-blade passage when going to the shroud region.

Higher fluctuation rates appear near the pressure side, up to $4 \%$, and in the vaneless diffuser with more pronounced variations near the shroud for which the boundary layers evolutions are different compared to the hub region ones. All these evolutions can be related with the mean absolute radial velocity contours plot in Figures 7(a) to 7(e). Near the pressure side regions, one can see that the radial velocity modifications are small. It has to be noted that the same kind of evolution is observed for the mean relative velocity contours. At the suction side region and near the hub $\left(b^{*}=0.128,0.256\right)$, the velocity fluctuation rates are lower (sometimes less than $2 \%)$ than in the pressure side. These low fluctuation rate zones are pushed away from the suction side to the main flow and higher levels extend in this area near the shroud for $b^{*}=0.871$. Looking once more to the absolute velocity contours on the upper part of Figures 7(a) to 7(e), it can be seen that the locations where the velocity gradients are important (vorticity changes) correspond to the local change of the fluctuation rates that are observed. Finally, in Figure 6 another part of the impeller outlet region is shown in order to have an image of the fluctuation rates at $b^{*}=0.5$.

This figure shows low levels of fluctuation rates (less than $1 \%)$ in the so-called passage wake that are completely different from those corresponding to the blade wake ( $7 \%$ to $10 \%)$.

For comparison between the PIV and LDV measurements, Figure 8 presents the fluctuation rates obtained with both techniques. Only the results for $r^{*}=0.818$ and 0.978 are given. For each radius, three locations in the hub-toshroud direction are studied as a function of the relative angular coordinate $\theta^{*}$ in the blade-to-blade direction. This figure shows low levels of fluctuation rates (less than $1 \%$ ) in the so-called passage wake that are completely different from those corresponding to the blade wake (7\% to $10 \%)$. 


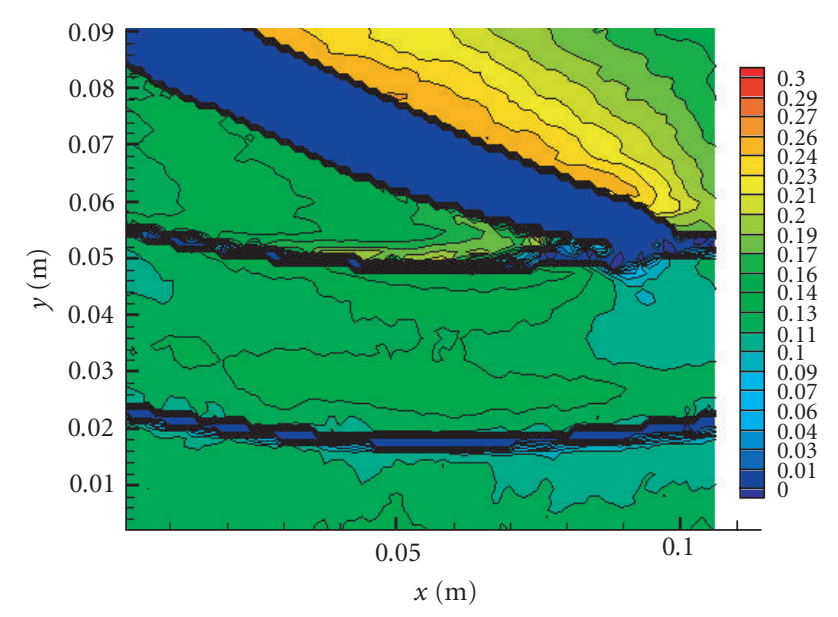

(a) $b^{*}=0.128$

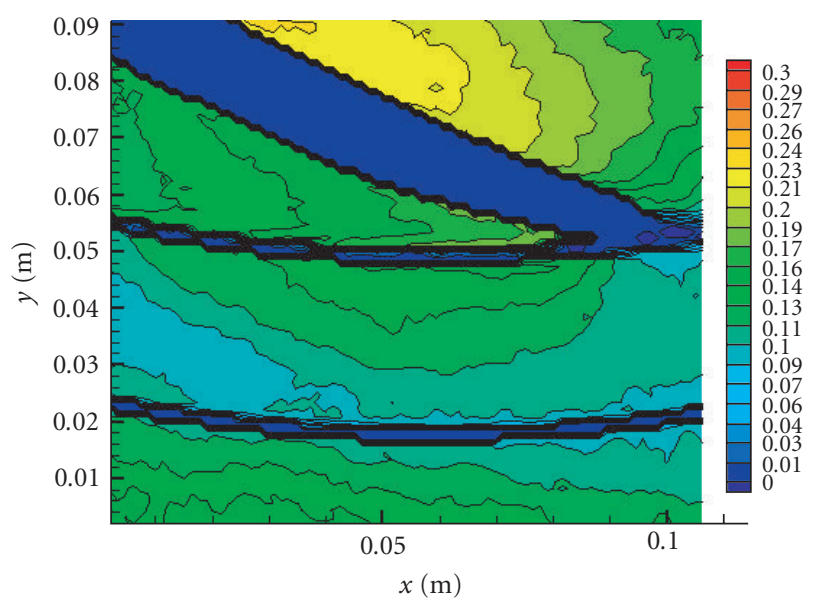

(c) $b^{*}=0.5$

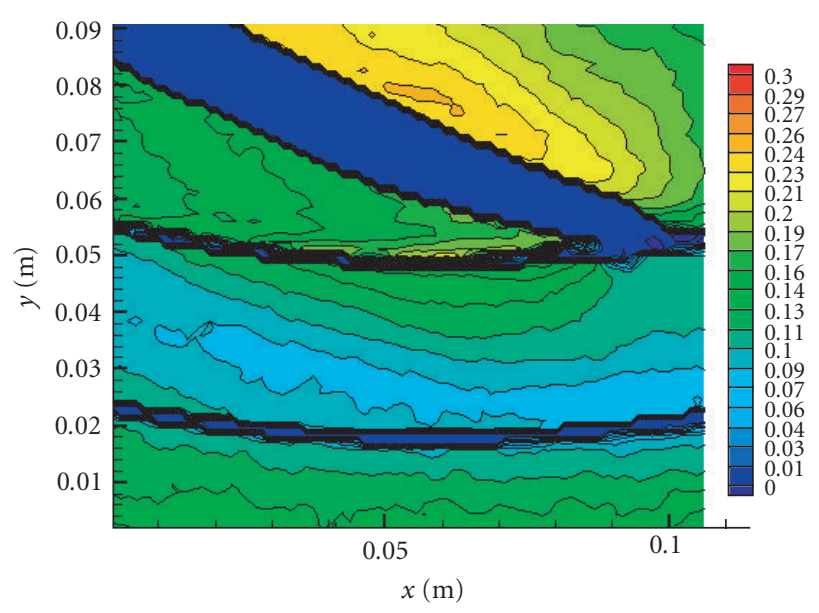

(b) $b^{*}=0.256$

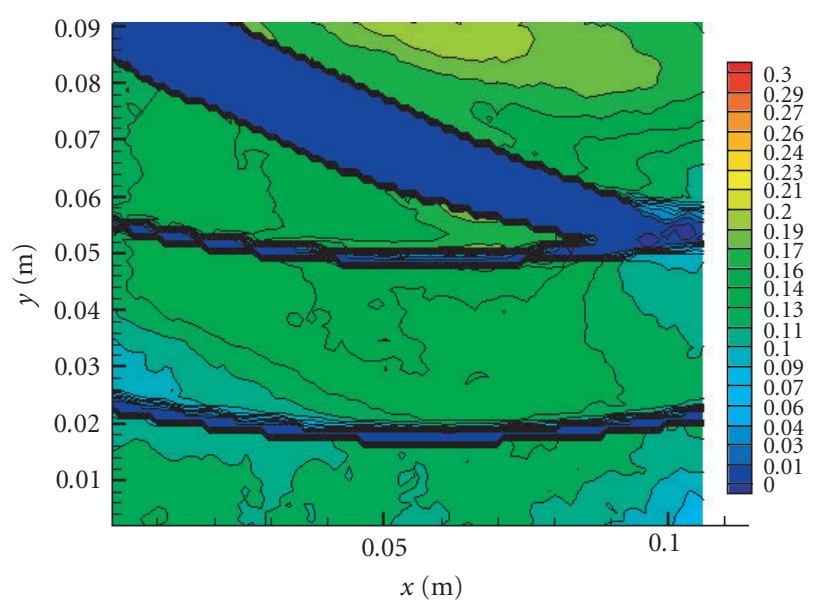

(d) $b^{*}=0.743$

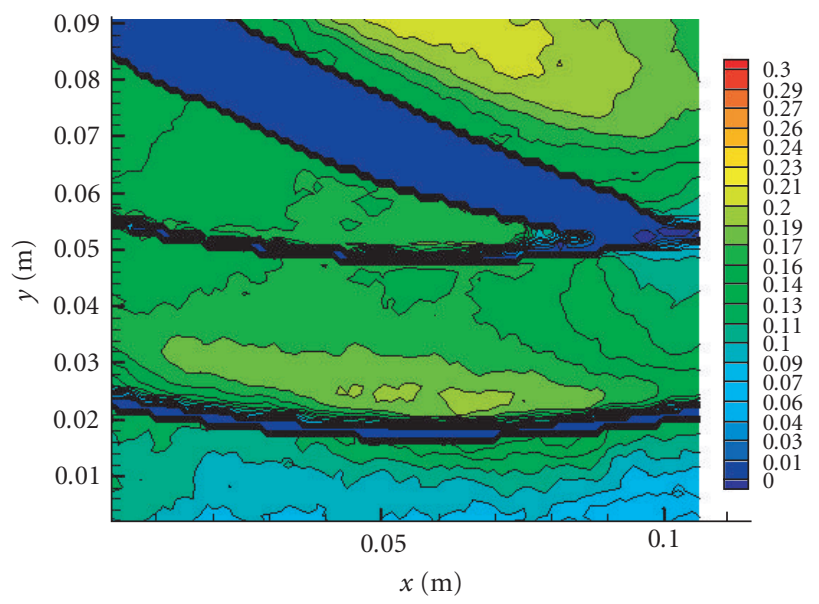

(e) $b^{*}=0.871$

Figure 7: Radial velocity.

For $r^{*}=0.818$, the fluctuation rate is higher with PIV measurement. At this radius and for $b^{*}=0.8$, slightly higher fluctuation rates registered between $\theta^{*}=0.6$ and 1 can be related to the local relative velocity difference as observed for LDV measurements in the same region (Figure 3(a)). As the impeller exit $\left(r^{*}=0.978\right)$ approaches the fluctuation rates for the air model remain of the same level as shown in Figure 8(b). On the contrary, the flow leaving the water 

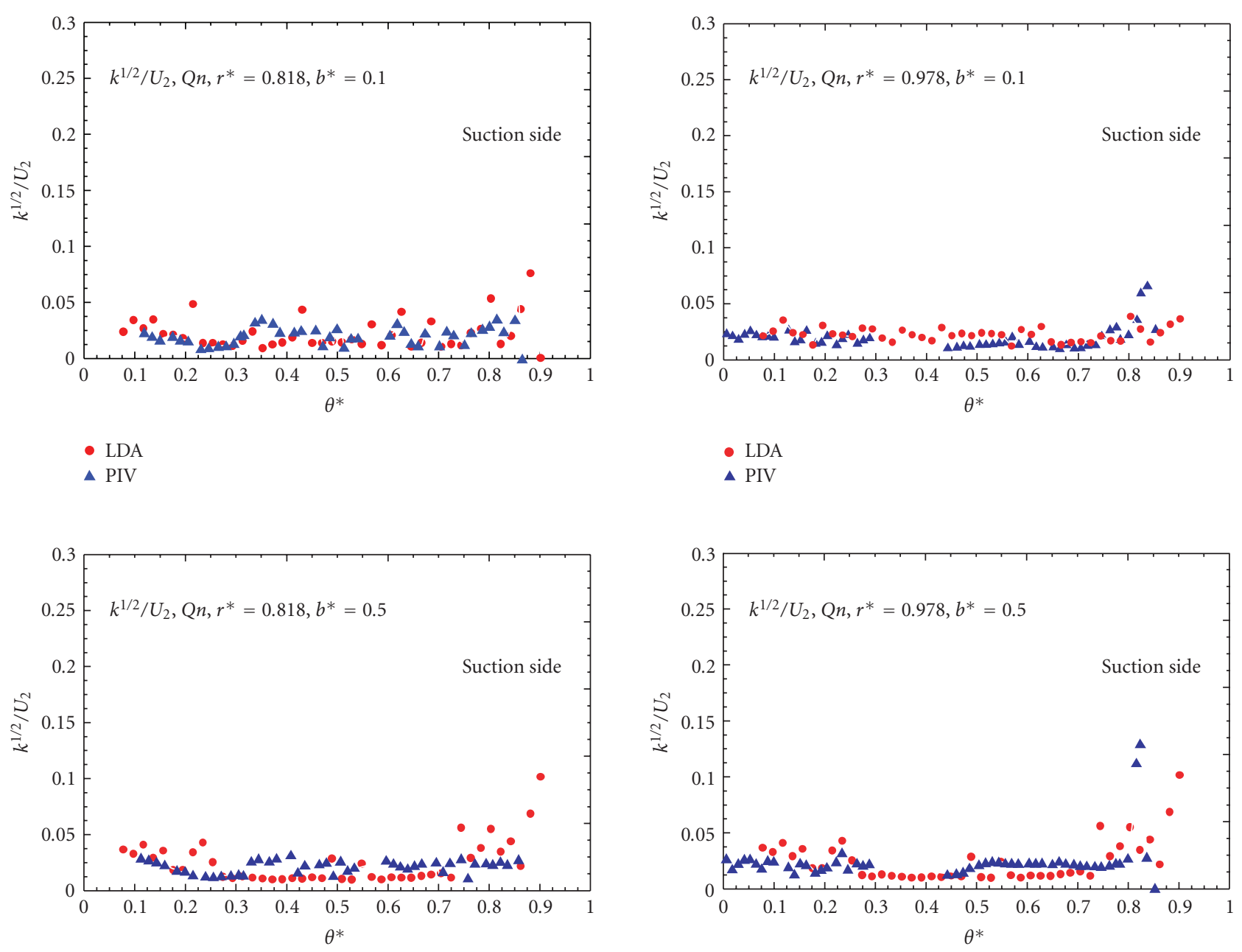

- LDA

- LDA

^ PIV

\ PIV
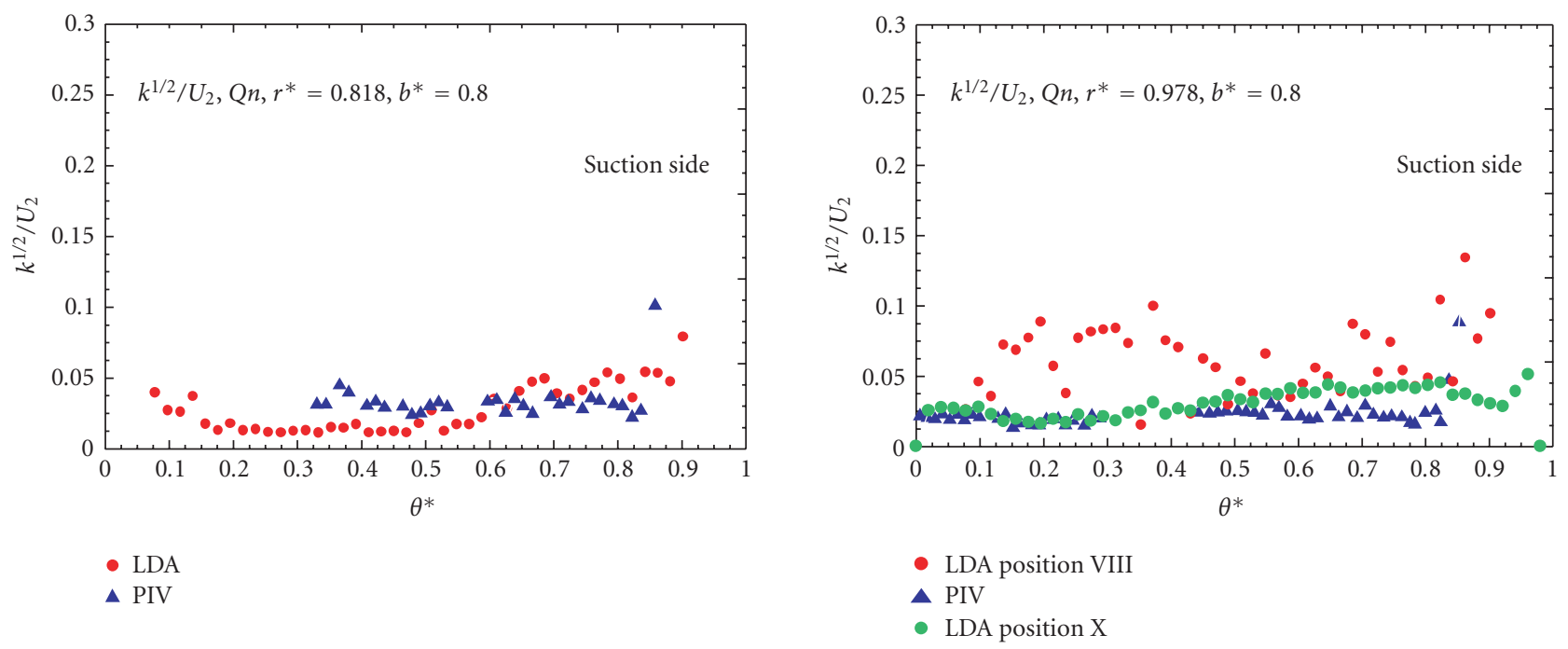

(a) K/U,Qn, $r^{*}=0.818$

(b) $\mathrm{K} / \mathrm{U}, \mathrm{Qn}, r^{*}=0.978$

FIGURE 8: Velocity fluctuation rates deduced from PIV and LDV measurements. 
model is characterised by higher fluctuation rates at $b^{*}=0.8$ as revealed by the LDV measurements (Figure $8(\mathrm{~b})$ ) near the pressure side of the impeller channels ( $\theta^{*}$ between 0 and 0.5 ).

In order to explain this sudden increase of $\mathrm{Tu}$, the results obtained in a different angular position relative to the diffuser vane (plane X in Figure 2) are reported in Figure 8(b) for $b^{*}=0.8$. It appears that for the water pump, the proximity of the vaned diffuser has an influence on the velocity fluctuation rate. The analysis of the full data (not presented in this paper) reveals that this influence is detected especially in plane VIII where the diffuser vane is in the trajectory of the flow leaving the rotor pressure side. Thus making this side of the impeller channel more sensitive to the proximity of the diffuser.

\section{CONCLUSION}

Detailed investigation of the internal flow within the SHF centrifugal impeller has been performed at design point with two different optical measurements techniques: PIV and LDV, respectively, in air and water test rigs. Both experimental techniques capture the particular jet and wake configuration generally observed in such radial impeller geometry. Besides the small differences for the location of the wake core, the flow fields are comparable. For the mean flow, the impeller internal flow can be considered as steady in spite of the vaneless and the vaned different configurations of the two test rigs. The most important difference relates to the velocity fluctuation rate more sensitive to the diffuser presence.

\section{ACKNOWLEDGMENTS}

This work is financially supported by several companies in a French research program coordinated by CIRT (Consortium Industrie Recherche Turbomachines), CNRS, and Région Nord Pas-de-Calais.

\section{NOMENCLATURE}

\begin{tabular}{|c|c|}
\hline B & Distance between laser sheet and the hub ( $\mathrm{m}$ \\
\hline $\mathrm{B}_{2}, \mathrm{~B}_{3}$ & Impeller outlet width and diffuser width (m) \\
\hline \multicolumn{2}{|l|}{$b^{*}=\mathrm{B} / \mathrm{B}_{2}$} \\
\hline$\overline{C_{r}}, \overline{C_{u}}$ & $\begin{array}{l}\text { Radial and peripheral component of phase } \\
\text { averaged absolute velocity }(\mathrm{m} / \mathrm{s})\end{array}$ \\
\hline$C_{r}^{\prime}, C_{u}^{\prime}$ & $\begin{array}{l}\text { Instantaneous radial and tangential velocity } \\
\text { fluctuation }(\mathrm{m} / \mathrm{s})\end{array}$ \\
\hline $\mathrm{K}=0.5\left[\overline{C_{r}^{\prime 2}}+\overline{C_{u}^{\prime 2}}\right]$ & Turbulent kinetic energy $\left(\mathrm{m}^{2} / \mathrm{s}^{2}\right)$ \\
\hline $\mathrm{N}$ & Speed of rotation (rpm) \\
\hline Q & Flow rate $\left(\mathrm{m}^{3} / \mathrm{s}\right)$ \\
\hline Q & Design flow rate $\left(\mathrm{m}^{3} / \mathrm{s}\right)$ \\
\hline $\mathrm{R}$ & Radius (m) \\
\hline $\mathrm{R}_{1}$ & Inlet tip radius of the impeller $(\mathrm{m})$ \\
\hline $\mathrm{R}_{2}$ & Outlet radius of the impeller $(\mathrm{m})$ \\
\hline
\end{tabular}

$\mathrm{R}_{3}$

$\mathrm{R}_{4}$

$\mathrm{R}_{5}$

$r^{*}=\mathrm{R} / \mathrm{R}_{2}$

$\mathrm{Re}=\mathrm{R}_{2} \mathrm{U}_{2} / \nu$,

$\mathrm{Tu}=\sqrt{\mathrm{K}} / \Omega \mathrm{R}_{2}$,

$\mathrm{U}_{2}=\Omega \mathrm{R}_{2}(\mathrm{~m} / \mathrm{s})$

$\mathrm{Z}$

$\Omega$

W

$\beta$

$\varphi$

$\psi$

$\omega_{s}$
First radial position of LDV measurements inside the vaneless diffuser

Vaned diffuser inlet radius

Last radial position of LDV measurement inside the vaned diffuser

Reynolds number

Nondimensional velocity fluctuation rate

Number of blades of the impeller

Impeller angular velocity $\left(\mathrm{s}^{-1}\right)$

Phase-averaged relative velocity $(\mathrm{m} / \mathrm{s})$

$\mathrm{W}$ angle relative to the tangential direction

Flow coefficient

Head coefficient

Pump specific speed.

\section{REFERENCES}

[1] S. M. Miner, R. J. Beaudoin, and R. D. Flack, "Laser velocimetry measurements in a centrifugal flow pump," Transactions of the ASME: Journal of Turbomachinery, vol. 111, no. 3, pp. 205212, 1989.

[2] C. H. Liu, C. Vafidis, and J. H. Whitelaw, "Flow characteristics of a centrifugal pump," Transactions of the ASME: Journal of Fluids Engineering, vol. 116, no. 2, pp. 303-309, 1994.

[3] M. Inoue and N. A. Cumpsty, "Experimental study of centrifugal impeller discharge flow in vaneless and vaned diffusers," Transactions of the ASME: Journal of Engineering for Gas Turbines and Power, vol. 106, no. 2, pp. 455-467, 1984.

[4] N. Arndt, A. J. Acosta, C. E. Brennen, and T. K. Caughey, "Experimental investigation Rotor-Stator interaction in a centrifugal pump with several vaned diffusers," Transactions of the ASME: Journal of Turbomachinery, vol. 112, no. 1, pp. 98-108, 1990.

[5] N. Hayashi, M. Koyama, and I. Ariga, "Study of flow patterns in vaneless diffusers of centrifugal compressors using PIV," in Proceedings of the 10th International Symposium on Applications of Laser Techniques to Fluid Mechanics, Lisbon, Portugal, July 2000.

[6] N. Paone, M. L. Riethmuller, and R. van den Braembussche, "Experimental investigation of the flow in the vaneless diffuser of a centrifugal pump by particle image displacement velocimetry," Experiments in Fluids, vol. 7, no. 6, pp. 371-378, 1989.

[7] K. Eisele, Z. Zhang, M. V. Casey, J. F. Gülich, and A. Schachenmann, "Flow analysis in a pump diffuser-part 1: LDA and PTV measurements of the unsteady flow," Transactions of the ASME: Journal of Fluids Engineering, vol. 119, pp. 968-977, 1997.

[8] G. D. Ciocan, V. Desvignes, J. F. Combes, E. Parkinson, and J. L. Kueny, "Experimental and numerical analysis of RotorStator interaction in a pump-turbine," in Proceedings of the 19th International Symposium on Hydraulic Machinery and Cavitation, Singapore, September 1998.

[9] M. Sinha and J. Katz, "Quantitative visualization of the flow in a centrifugal pump with diffuser vanes-I: on flow structures and turbulence," Transactions of the ASME: Journal of Fluids Engineering, vol. 122, no. 1, pp. 97-107, 2000. 
[10] N. Pedersen and C. B. Jacobsen, "PIV investigation of the internal flow structure in a centrifugal pump impeller," in Proceedings of the10th International Symposium on Applications of Laser Techniques to Fluid Mechanics, Lisbon, Portugal, July 2000.

[11] A.-R. Akhras, "Etude de l'interaction roue-diffuseur dans une pompe centrifuge," Thèse de Doctorat, Institut National des Sciences Appliquées de Lyon, Lyon, France, 2002.

[12] G. Wuibaut, "Etude de par vélocimétrie par images de particules des interactions rouediffuseur dans une pompe centrifuge," Thèse de Doctorat, Ecole Nationale Supérieures d'Arts et Métiers Centre de Lille, Lille, France, 2001.

[13] G. Wuibaut, P. Dupont, G. Caignaert, and M. Stanislas, "Experimental analysis of velocities in the outlet part of a radial flow pump impeller and the vaneless diffuser using particle image velocimetry," in Proceedings of the 20th IAHR Symposium on Hydraulic Machinery and Systems, Charlotte, NC, USA, August 2000.

[14] A.-R. Akhras, M. El Hajem, R. Morel, and J. Y. Champagne, "Internal flow investigation of a centrifugal pump at the design point," Journal of Visualization, vol. 4, no. 1, pp. 91-98, 2001.

[15] M. El Hajem, A. Akhras, R. Morel, and J. Y. Champagne, "The Rotor-Stator interaction in a centrifugal pump equipped with a vaned diffuser," in Proceedings of the 4th European Conference on Turbomachinery Fluid Dynamics and Thermodynamics, Firenze, Italy, March 2001.

[16] G. Wuibaut, P. Dupont, G. Bois, G. Caignaert, and M. Stanislas, "Analysis of flow velocities within the impeller and the vaneless diffuser of a radial flow pump," in Proceedings of the 4th European Conference on Turbomachinery, Fluid Dynamics and Thermodynamics, Firenze, Italy, March 2001.

[17] D. Eckardt, "Instantaneous measurements in the jet-wake discharge flow of a centrifugal compressor impeller," Transactions of the ASME: Journal of Engineering for Power, vol. 97, no. 3, pp. 337-346, 1975.

[18] M. Ubaldi, P. Zunino, and A. Cattanei, "Relative flow and turbulence measurements downstream of a backward centrifugal impeller," Transactions of the ASME: Journal of Turbomachinery, vol. 115, pp. 543-551, 1993. 

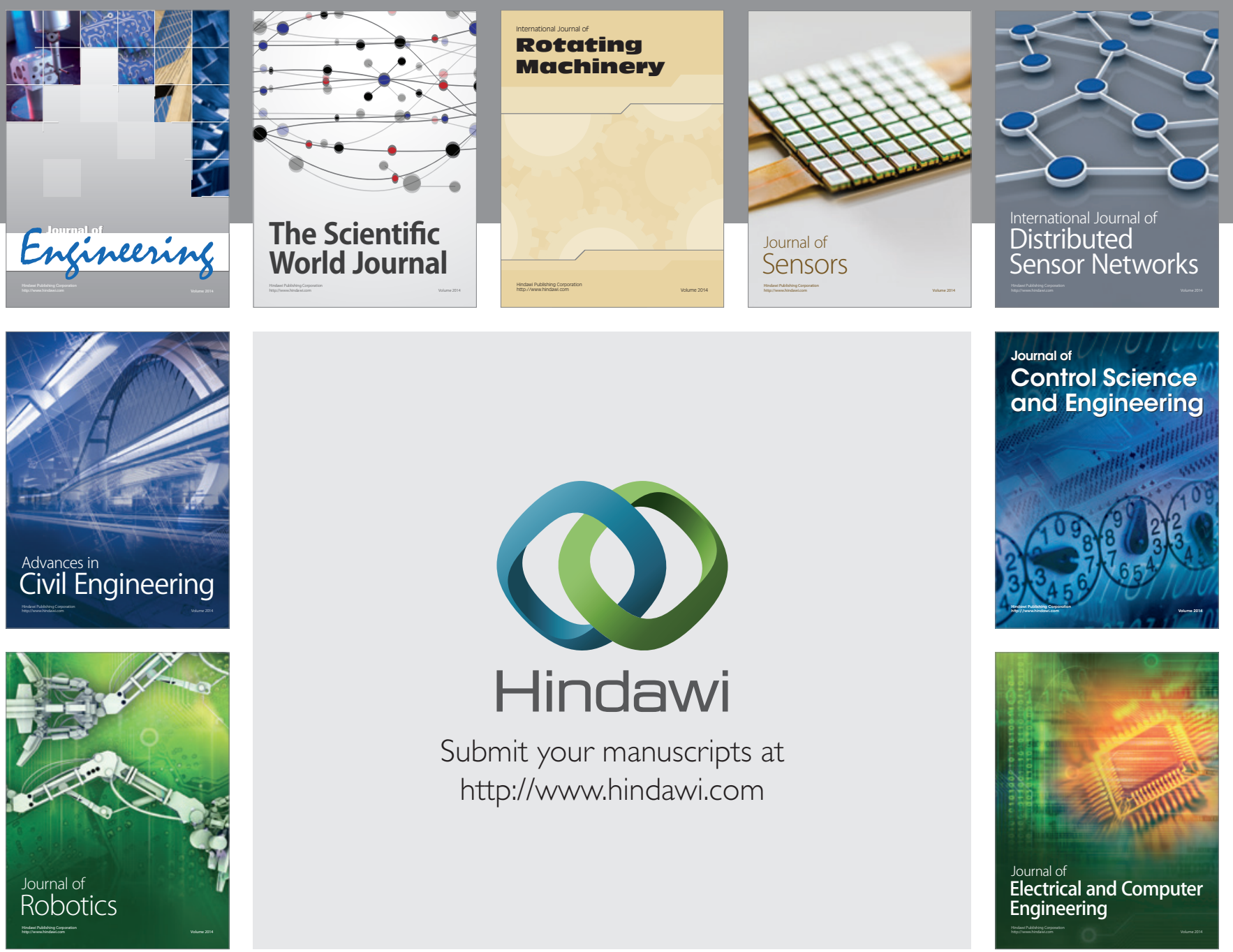

Submit your manuscripts at

http://www.hindawi.com
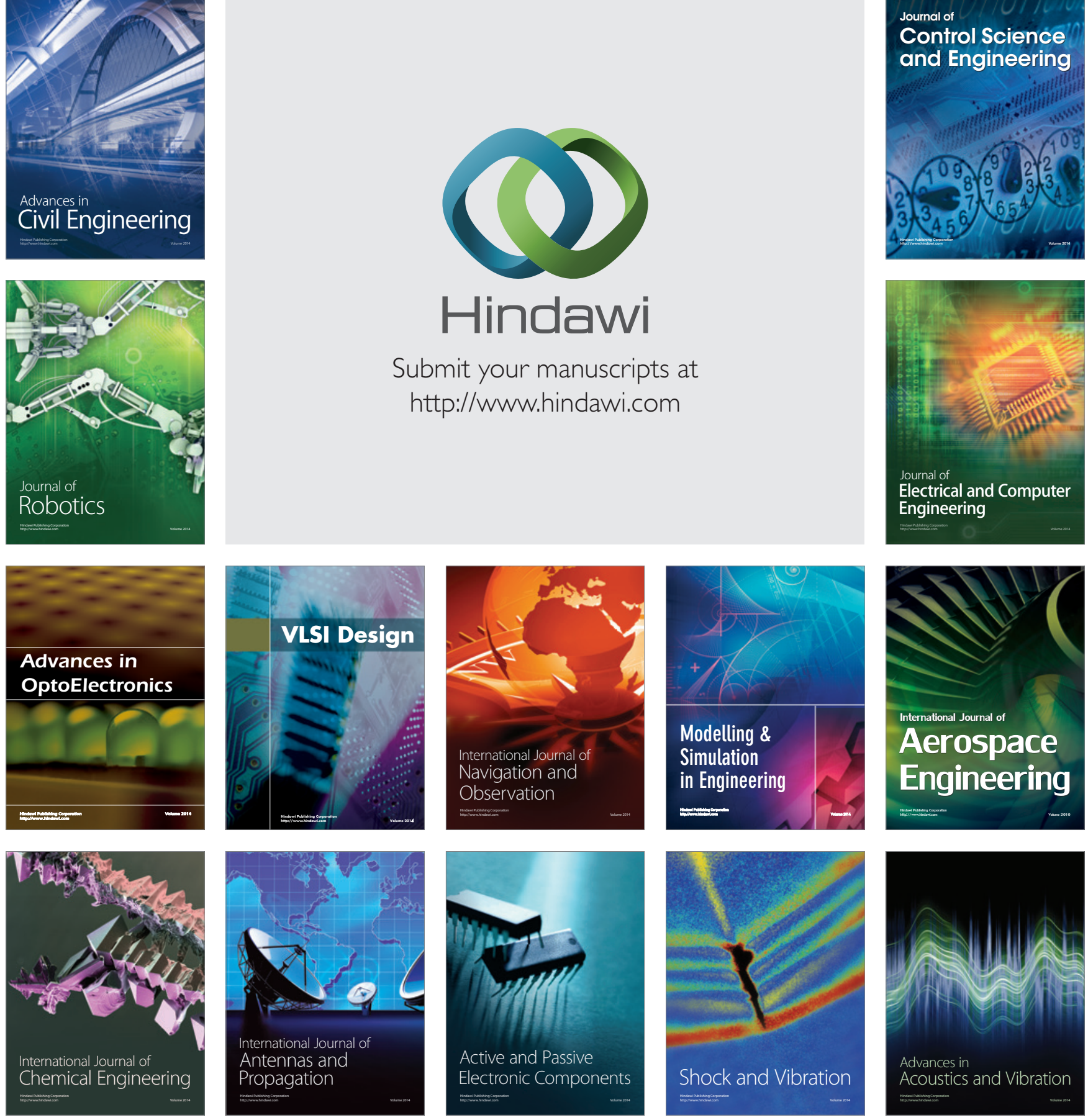